\title{
A new species of Heterotrissocladius Spärck, 1923 (Diptera: Chironomidae: Orthocladiinae) from Georgia, USA
}

\author{
Broughton A. CALDWELL, ${ }^{1,2^{*}}$ Richard E. JACOBSEN ${ }^{3}$ \\ 12645 Muskogee Lane, Braselton, GA 30517; ${ }^{2}$ Research Associate, Florida State Collection of Arthropods, Gainesville, FL 32614; \\ ${ }^{3} 1828$ SW Centerville Avenue, Fort White, FL 32038, USA \\ *Corresponding author: bacaldwell@mindspring.com
}

\begin{abstract}
Heterotrissocladius spiesi sp. n. is described from headwaters of two small Georgia streams, below the Fall Line in the Coastal Plain Physiologic Province, Atlantic Slope drainage. One stream is near the coast (Lower Coastal Plain) and characterized as a "blackwater" stream due to high tannin concentrations. The other stream is inland (Upper Coastal Plain), clear and not noticeably affected by tannins. The description is based on adult males, pharate male pupae and one attached larval skin. The new species is assignable to the $H$. marcidus species group with some exceptions. Males differ from the previous group by a reduced number of rather weak, short acrostichal setae (0-3, previously considered as typical of the subpilosus group) as well as by a very reduced wing squamal fringe compared to most members of the $H$. marcidus group. Males are recognizable by an elongate, thin virga, distinctive anal point and inflated/triangular gonostylus. The female is not described; the immature stages are very similar in some features to $H$. boltoni Sæther. At the inland stream, an adult male of the new species was found together with pharate male pupae (one with larval skin) of another, as yet undetermined species of Heterotrissocladius (marcidus group) also known from elsewhere in the state. Female adults and a pharate female pupa collected at the blackwater stream site are noted but not included in the description or type series.
\end{abstract}

Key words: Diptera, Chironomidae, Orthocladiinae, Georgia, Heterotrissocladius marcidus species group.

Received: February 2018. Accepted: April 2018.

This paper was presented at the $20^{\text {th }}$ International Symposium on Chironomidae, Trento, Italy, 2-8 July 2017. Session: Taxonomy and Systematics.

\section{INTRODUCTION}

During March 1986 and 1987 an apparently undescribed species assignable to the Heterotrissocladius marcidus species group (Sæther 1975, 1988, 1992) was discovered in a headwater reach of a blackwater lower Coastal Plain stream (Big Creek). Sampling in headwaters of a small, clear, upper Coastal Plain stream (Red Hill Creek) in February 1992 yielded one male of the above species occurring with another apparently undescribed Heterotrissocladius species known from elsewhere in the state. Both streams are below the Fall Line in the Atlantic Slope drainage. The following description is based on adult males, three pharate male pupae, one with attached larval skin.

Ashe and O'Connor (2012) listed twenty-two species of Heterotrissocladius considered as valid and three nomina dubia probably belonging to the genus. Since then, $H$. simmiensis Makarchenko and Makarchenko has been described in addition (Yavorskaya et al., 2016). Based on comparisons with the corresponding published descriptions, our specimens first found in Big Creek represent an additional, previously undescribed species.

\section{METHODS}

Morphological terminology generally follows Sæther (1980), Oliver and Dillon (1989) and Langton (1994). Counts and measurements were made following Soponis (1977), except that concerning wing features the respective left one was used. Measurements are given in $\mu \mathrm{m}$ unless stated otherwise, and reported as the respective minimum, maximum and mean value when 3 or more specimens were measured. The number of specimens or structures measured/counted (n) is given in parentheses. The terms $\mathrm{L}_{\mathrm{ex}}$ and $\mathrm{P}_{\mathrm{ex}}$ are used for larval skins and pupal exuviae, respectively. Specimens were mounted in Canada balsam after dissection and clearing.

The holotype and eight paratypes are deposited in the William L. Peters Museum Collection of Aquatic Insects at Florida A \& M University, Tallahassee, Florida (part of the Florida State Collection of Arthropods - FSCA). Additional non-type material is in the collection of the senior author (BAC).

Heterotrissocladius spiesi Caldwell \& Jacobsen sp. n.

Etymology. The species is named in honor of our 
mutual friend and colleague Martin Spies, Zoologische Staatssammlung, Munich, Germany for the many instances of his untiring assistance with literature and sharing of knowledge of chironomid systematics over several decades.

Type material. Holotype: male, USA: Georgia: Ware County: Big Creek upstream Braganza Road (previously Shirley Rd.) N31.1469 W82.2513, 18-III-1987, leg. B. A. Caldwell. Paratypes: same data as holotype except, 4 males (one reared from pupa with exuviae), 1 pharate male pupa. One male and 1 pharate male pupa, $L_{e x}$ attached, Big Creek upstream of L. S. Walker State Park, N31.1461 W82.2260, 26-III-1986, leg. B. A. Caldwell. Laurens County: Red Hill Creek upstream Georgia Highway 199, N32.3943 W82.7248, 21-II-1992; 1 male, leg. B. A. Caldwell.

Diagnostic characters. The male can be separated from other members of the $H$. marcidus species group by the following combination of features: thorax with 0 to 4 short, curved, rather weak acrostichal setae; wing membrane with setae mostly on distal half, wing anal lobe slightly developed; squamal fringe very reduced with 35, 4 setae, anal point elongate, tapered with rounded apex; virga very thin, elongate, tapered in distal half and terminating in a sharp point; gonostylus inflated, triangular, apparently without crista dorsalis. The distinctive hypopygium alone would suffice to separate the new species from all other members of the genus. The adult female is not described here, due to uncertain association. The immature stages are similar to those of H. boltoni Sæther, 1992, and the pupae are separable by lacking frontal warts and frontal setae. No differences have been recognized to definitively separate the larvae.

\section{Description.}

Male $(\mathrm{n}=6)$. Body size small, abdomen length 1.70$1.82,1.74 \mathrm{~mm}$. Overall coloration in Canada balsam mostly light to medium brown; thorax generally darkest, abdominal segments 6-8 lighter posteriorly, legs without markings; wings unmarked with pale veins.

Head (Fig. 1). Temporal setae 6-8, 7, including 2 inner verticals, 3-5, 4 outer verticals and 0-2, 1 postorbitals; clypeal setae 4-7, 5. AR 0.79-0.94, 0.84. Maxillary palp with 5 palpomeres; lengths of palpomeres 19-25, 20; 27 38, 32; 93-115, 101; 79-90, 84; 110-129, 119.

Thorax (Fig. 2). Setae: lateral antepronotals very small, 4-6, 5; acrostichals $0-4,1$, if present all situated anteriorly; dorsocentrals 4-6, 5; prealars 3-5, 4; scutellars 4-6, 5 .

Wing (Fig. 3). Wing length 1.42-1.61, $1.47 \mathrm{~mm}$. Anal lobe slightly developed. Vein setae: brachiolum 2; R 14-18, $17 ; \mathrm{R}_{1} 7-13,10 ; \mathrm{R}_{4+5} 19-31,24 ; \mathrm{M}_{1+2} 26-48,37 ; \mathrm{M}_{3+4} 13-$ 25, 20; Cu 1-9, 4; $\mathrm{Cu}_{1} 3-10$, 6; vannal fold 2-10, 6. Cell setae: $\mathrm{r}_{4+5} 55-97,73 ; \mathrm{m}_{1+2} 47-98,67 ; \mathrm{m}_{3+4} 14-46$; cu $0-3,1$; an 1-4, 2. Squama with 3-5, 4 setae. VR 1.05-1.13, 1.08.

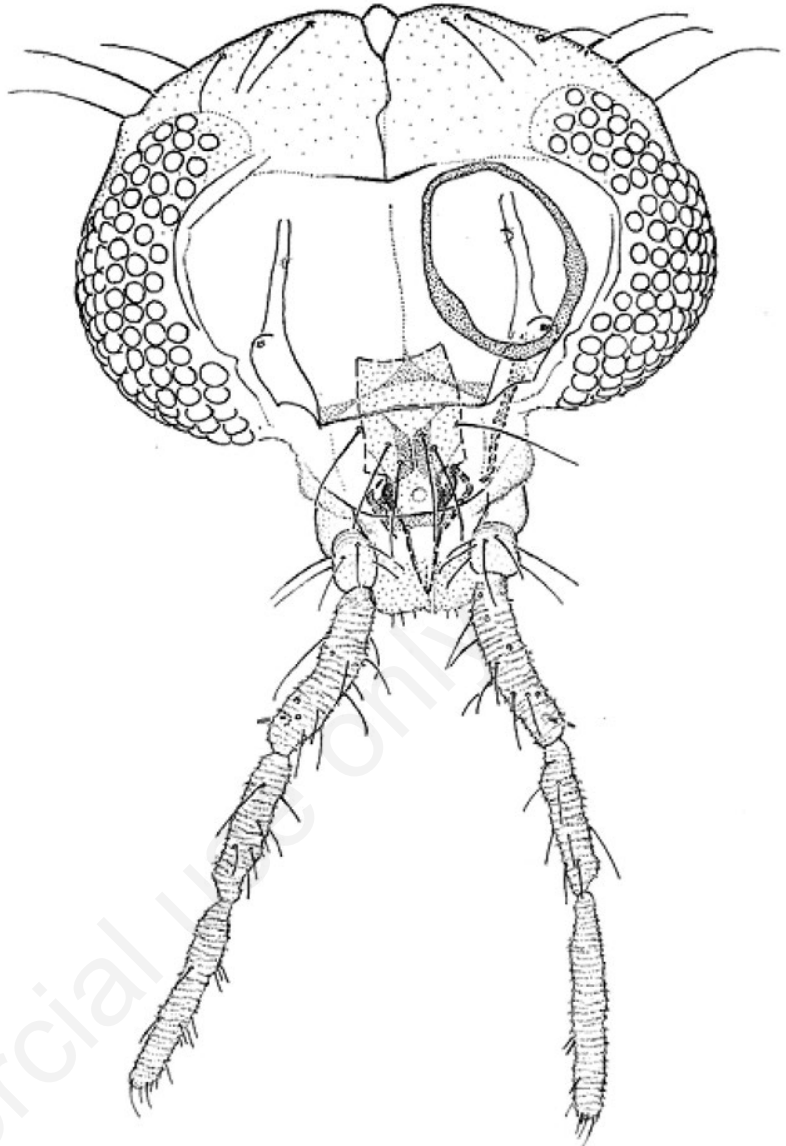

Fig. 1. Heterotrissocladius spiesi sp. n. Caldwell \& Jacobsen. Head, frontal.

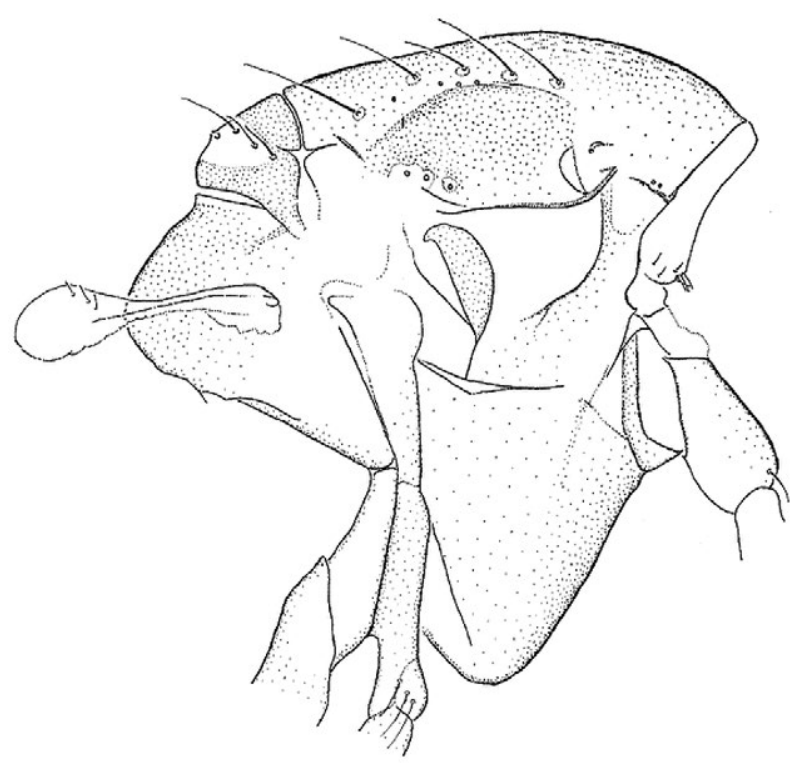

Fig. 2. Heterotrissocladius spiesi sp. n. Caldwell \& Jacobsen. Thorax, dorsolateral. 
Legs. Lengths and ratios in Tab. 1. Fore tibial spur simple, slightly curved, 25-41, 35 long, Mid and hind tibial spurs simple, straight; mid tibial spurs 22-27, 26 and 19-22, 21 long; hind tibial spurs 47-52, 48 and 16-25, 19 long. Hind tibial comb with $7-9,8$ spines. Sensilla chaetica absent.

Hypopygium (Fig. 4). Anal point long, gently tapering to rounded apex, mostly microtrichiose and with

Tab. 1. Leg measurements $(\mu \mathrm{m})$ and ratios for male Heterotrissocladius spiesi.

\begin{tabular}{lccc}
$(\mathrm{n}=6)$ & $\mathrm{p}_{1}$ & $\mathrm{p}_{2}$ & $\mathrm{p}_{3}$ \\
$\mathrm{fe}$ & $590-682,617$ & $579-677,622$ & $584-710,632$ \\
\hline $\mathrm{ti}$ & $644-753,673$ & $584-666,608$ & $672-797,698$ \\
\hline $\mathrm{ta} 1$ & $513-601,545$ & $322-366,337$ & $404-459,420$ \\
\hline ta2 & $267-317,284$ & $153-180,162$ & $191-235,207$ \\
\hline ta3 & $202-240,214$ & $115-136,123$ & $158-191,169$ \\
\hline ta4 & $136-158,145$ & $76-87,81$ & $87-109,95$ \\
\hline ta5 & $71-76,75$ & $65-71,68$ & $65-71,69$ \\
\hline LR & $0.79-0.81,0.81$ & $0.54-0.57,0.55$ & $0.57-0.64,0.60$ \\
\hline BV & $2.51-2.60,2.55$ & $3.47-3.72,3.61$ & $3.19-3.32,3.24$ \\
\hline SV & $2.28-2.60,2.37$ & $3.55-3.75,3.65$ & $3.04-3.28,3.16$
\end{tabular}

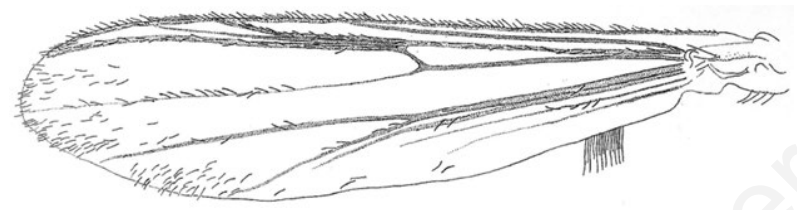

Fig. 3. Heterotrissocladius spiesi sp. n. Caldwell \& Jacobsen. Wing, dorsal.

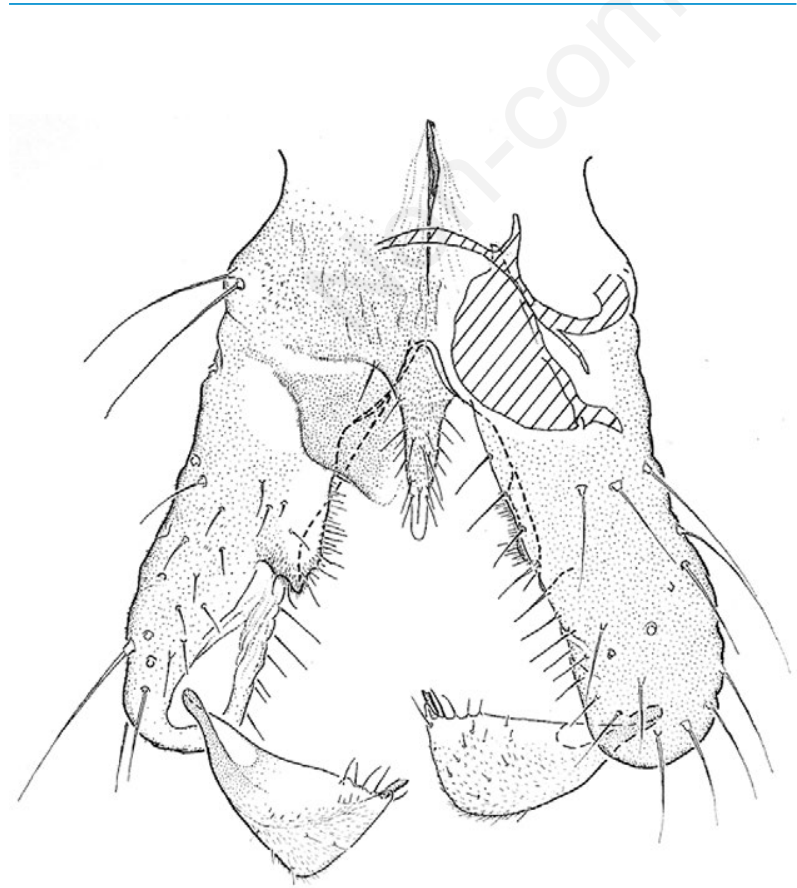

Fig. 4. Heterotrissocladius spiesi sp. n. Caldwell \& Jacobsen. Hypopygium, dorsal view left, ventral view right with internal structures.
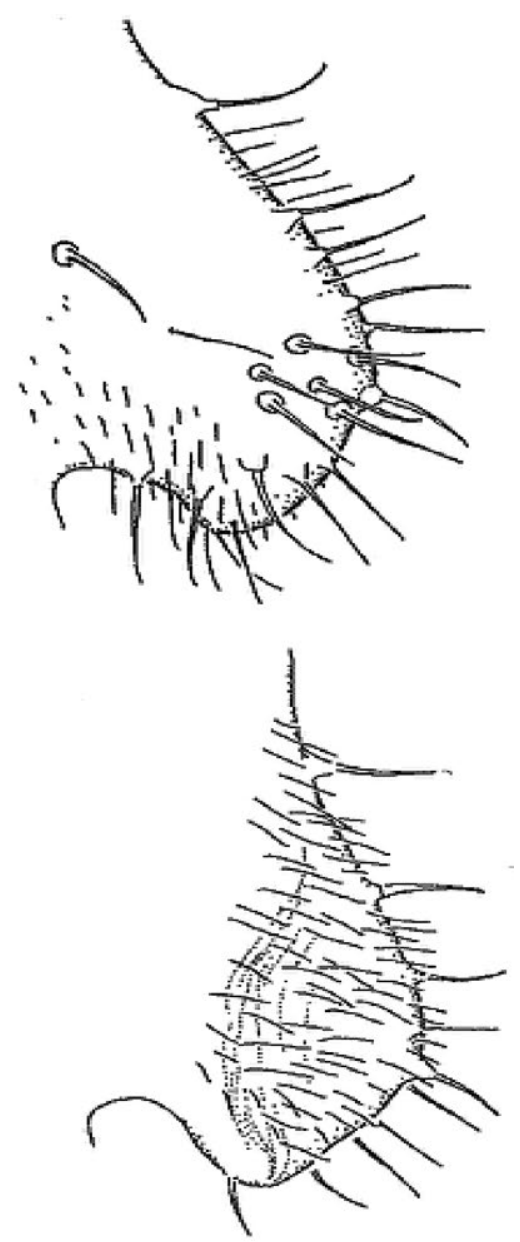

Fig. 5. Heterotrissocladius spiesi sp. n. Caldwell \& Jacobsen. Inferior volsella, (upper) dorsal and (lower) ventral. 
scattered setae, but distal fifth bare. Gonocoxite 225-233, 227 long, superior volsella barely indicated as a basal collar, inferior volsella directed caudally, somewhat variable (Figs. 4 and 5). Gonostylus 77-85, 82 long, subtriangular due to distal inflation, without evidence of a crista dorsalis. Megaseta 11-14, 13 long. Transverse sternapodeme 47-57, 54 wide with prominent lateral projections to anterior; phallapodeme 68-77, 72 long, half-moon shaped due to strongly convex median lamella. Virga compact, very thin and 47-57, 54 long, terminating in a sharp point.

Female. Not definitively associated by rearing in isolation, therefore not described here.

Pupa (pharate male, $n=3$ except where noted).

Cephalothorax (Fig. 6) of exuviae light yellowish brown, abdomen very pale yellow (in balsam). Total length of exuviae $2.82 \mathrm{~mm}(\mathrm{n}=1)$; length of cephalothorax $0.87 \mathrm{~mm}$, of abdomen $1.95 \mathrm{~mm}$.

Head with frontal apotome mostly smooth with few lines/wrinkles; frontal warts absent, frontal setae (or their sockets) also apparently lacking. Antepronotum with two median setae about 60-63 long $(\mathrm{n}=1)$, and with two apparently shorter lateral setae present (exact lengths not measurable). Suture area with rugosity weak anterodorsally, diminishing posteriorly. Thoracic horn 260-285, 271 long, 30-33, 31 wide with lateral spines/spinules on most of its length, apex ending in a sharp point. Distance from $\mathrm{D}_{\mathrm{c} 1}$ to $\mathrm{D}_{\mathrm{c} 2}, 8-11$ (10); from $\mathrm{D}_{\mathrm{c} 2}$ to $D_{c 3}, 11$; from $D_{c 3}$ to $D_{c 4} 33-47(39)$. Tip of wing sheath entirely smooth.

Abdomen. Generally similar to $H$. boltoni Sæther (1992, Fig. 3 C,D). Armament: segment I unarmed; II with around 12 caudal hooklets grouped in a relatively tight central cluster; segments II-VI with dorsal shagreen over much of semment, becoming widest posteriorly, sternites apparently without shagreen, except on VI; VIIVIII with dorsal shagreen much reduced, especially on VIII, sternites apparently without shagreen but sternite VIII with small posterior spines. Lateral setation: segment with 1 seta; II-VI with 3 setae each; VII-VIII with 4 and 5 taeniae, respectively; anal lobe with about 15-19, 17 fringe taeniae and 3 thin, slightly curved anal macrosetae. Pedes spurii B well developed, rounded on segment II. Pedes spurii A not evident. Male genital sac extending past anal lobe.

Larva ( $\mathrm{n}=1, \mathrm{~L}_{\mathrm{ex}}$ attached to pharate male pupa).

Head. Coloration (in balsam) light yellowish brown with premandibles, much of mandibles, mentum and ventromental plates medium brown. Head width about 274. Antenna (Fig. 7). Segment lengths: 44, 19, 4, 14, 4, 4 with $7^{\text {th }}$ segment barely indicated, vestigial; blade not quite reaching apex of segment 4; AR 0.98. Basal segment 12 wide, distance from base to ring organ 7. Style, other features not clearly discernible. Premandible (Fig. 8) 55 long, slightly bifid at apex. Labral features not sufficiently visible/discernible; SI setae appearing to curve forward and partially downward, widest apically with about 10 projections/teeth. Pecten epipharyngis consisting of 3 short, slender spines with jagged apices, the median spine extending farther posterior than the others. Mandible 112 long. Mentum (Fig. 9) moderately arched with 2 rounded median teeth. Submentum area (gula) not darkened.

Body. Anterior parapods separate with some shorter

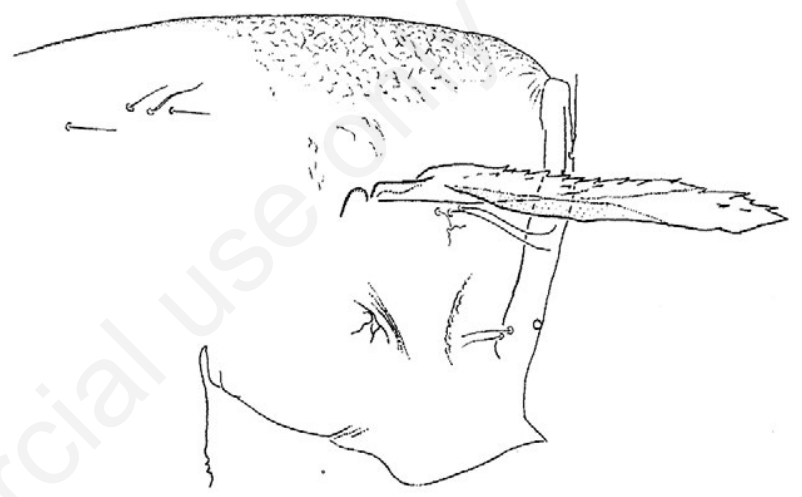

Fig. 6. Heterotrissocladius spiesi sp. n. Caldwell \& Jacobsen. Pupal thorax, lateral.

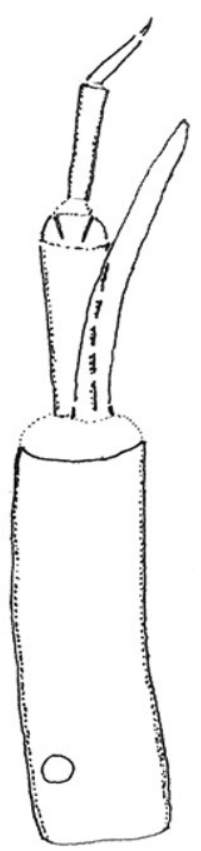

Fig. 7. Heterotrissocladius spiesi sp. n. Caldwell \& Jacobsen. Antenna. 
claws exhibiting fine teeth distally. Posterior parapods with about 14 simple, pale claws. Procerci short, lightly sclerotized, more or less trapezoidal, each with about 6 or 7 anal setae. Supraanal setae 77 long. Anal tubules not discernible. Body setae appearing very sparse.

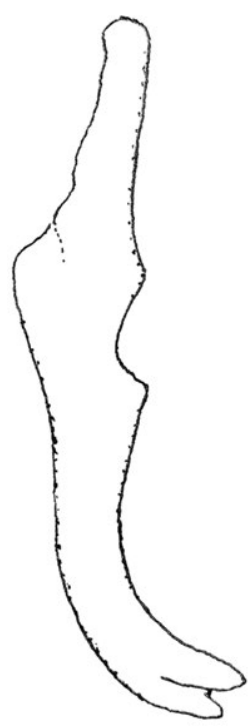

Fig. 8. Heterotrissocladius spiesi sp. n. Caldwell \& Jacobsen. Premandible.

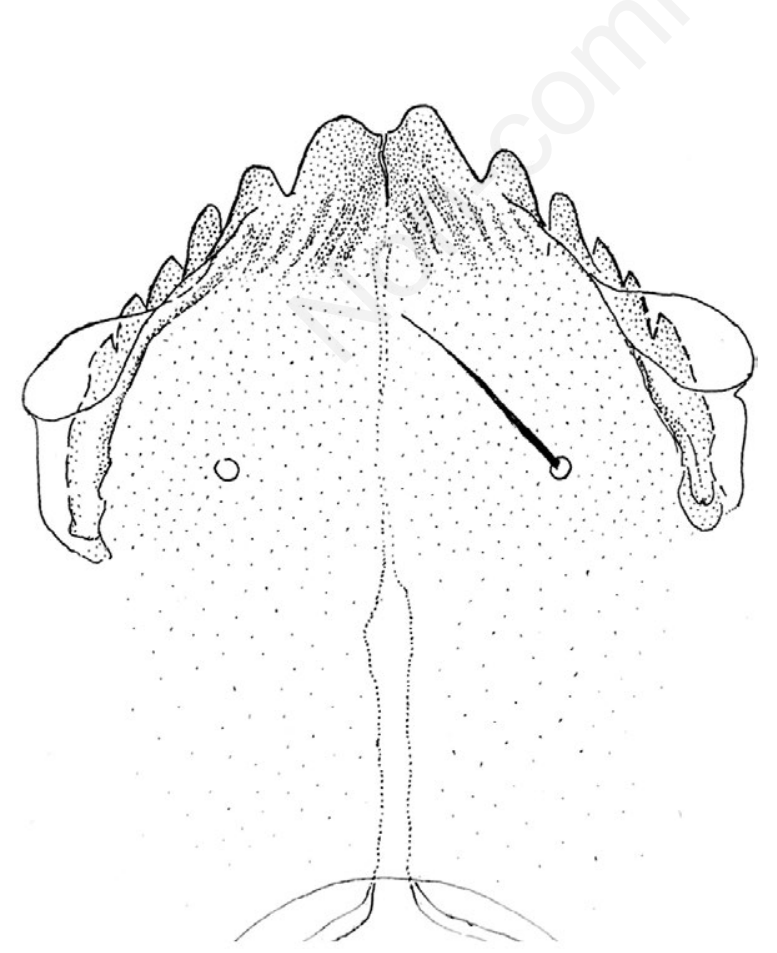

Fig. 9. Heterotrissocladius spiesi sp. n. Caldwell \& Jacobsen. Mentum and postmentum.
Distribution. At present known only from two Georgia streams. The species should be expected to occur in other Coastal Plain streams of Georgia and probably other southeastern/eastern states during winter months.

\section{DISCUSSION}

Immature stages of the new species were collected at the Big Creek site only, whereas all Heterotrissocladius immature stages taken at Red Hill Creek appear to belong to another, possibly also new species. The immature stages from both streams appear to be very similar, and to share some features with $H$. boltoni such as the pupa with 5 lateral taeniae on segment VIII (unique within the $H$. marcidus group), lacking wing sheath pearl rows, etc. The latter species has been reported from vernal pools and streams in Ohio only. The Big Creek $\mathrm{L}_{\mathrm{ex}}$ of $H$. spiesi fits the previously defined $H$. marcidus group. Epler (2001) gave this specimen the temporary name $H$. sp. "Caldwell" and was unable to separate it from $H$. boltoni (e.g., SI setae oriented similarly in $H$. boltoni that we have examined look much the same as in $H$. spiesi) and we agree. The pharate female pupa from Red Hill Creek is not in sufficient condition for meaningful comparison either. Additional reared specimens are needed for study.

\section{ACKNOWLEDGEMENTS}

The authors thank John Epler, Crawfordville, Florida USA and Martin Spies, Munich, Germany for their inputs and discussions of the manuscript. We also thank Mike Bolton, Ohio EPA, Groveport, OH USA for a loan of several $H$. boltoni specimens and two anonymous reviewers for very helpful comments and suggestions.

\section{REFERENCES}

Ashe P, O'Connor JP, 2012. A world catalogue of Chironomidae (Diptera). Part 2. Orthocladiinae. Irish Biogeographical Society and National Museum of Ireland, Dublin: 968 pp.

Epler JH, 2001. Identification manual for the larval Chironomidae (Diptera: Chironomidae) of North and South Carolina. A guide to the taxonomy of the midges of the southeastern United States, including Florida. Special Publication SJ2001-SP13. North Carolina Department of Environment and Natural Resources, Raleigh - St. Johns River Water Management District, Palatka: 526 pp.

Langton PH, 1994. If not "filaments", then what? Chironomus 6:1-9.

Oliver DR, Dillon ME, 1989. The adult males of Chironomidae (Diptera) of the Holarctic region - key to subfamilies, p. 1115. In: T. Wiederholm (ed.), Chironomidae of the Holarctic region. Keys and diagnoses. Part 3 - Adult males. Entomological Society of Lund, Sweden. 
Sæther OA, 1975. Nearctic and Palaearctic Heterotrissocladius (Diptera: Chironomidae). Bull. Fish. Res. Bd. Can. 193: 1-67.

Sæther OA, 1980. Glossary of chironomid morphology terminology (Diptera: Chironomidae). Ent. Scand. Suppl. 14:1-51.

Sæther OA, 1988. Heterotrissocladius brundini spec. nov. from Norway (Diptera: Chironomidae). Spixiana Suppl. 14:57-64. Sæther OA, 1992. Heterotrissocladius boltoni sp. n., a new orthoclad from vernal pools and streams in Ohio, USA (Diptera: Chironomidae). Neth. J. Aquat. Ecol. 26:191-196.

Soponis AR, 1977. A revision of the Nearctic species of Orthocladius (Orthocladius) van der Wulp (Diptera: Chironomidae). Mem. Ent. Soc. Canada 102:1-187.

Yavorskaya NM, Orel OV, Makarchenko MA, Makarchenko EA, 2016. [The chironomid fauna (Diptera, Chironomidae) of the Bolonsky Nature Reserve (Khabarovsk Territory)].[Article in Russian].Euroasian Ent. J. 15:201-210. 